\title{
ROLE OF B SCAN IN OPHTHALMIC TRAUMA
}

\author{
Indra Kumar Batham ${ }^{1}$, Ratnesh Jain², Vivek Kumar Soni³
}

${ }^{1}$ Assistant Professor, Department of Radiodiagnosis, G. R. Medical College and J. A. Group of Hospitals, Gwalior.

${ }^{2}$ Assistant Professor, Department of Radiodiagnosis, G. R. Medical College and J. A. Group of Hospitals, Gwalior.

3Junior Resident, (PG Resident) Department of Radiodiagnosis, G. R. Medical College and J. A. Group of Hospitals, Gwalior.

\begin{abstract}
BACKGROUND

Trauma to the eye has a profound impact on the mental, socioeconomic and spiritual aspects of a person. The B-scan ultrasonography makes a pictorial representation of the cross section of the eye. The globe is the dominant structure in the anterior orbit and its cystic structure and superficial position is ideal for ultrasound examination. Ultrasonography has the advantage of non-invasiveness, rapidity, easy accessibility and can be done in real time making it invaluable for assessment of ophthalmic trauma. Hence, this study will attempt to assess the role of sonography as an imaging modality of choice in the diagnosis and evaluation of ophthalmic trauma.
\end{abstract}

\section{MATERIALS AND METHODS}

This is a study of 100 cases of ocular trauma by B-scan. This study was conducted in Department of Radiodiagnosis in Gajra Raja Medical College \& Jayarogya Group of Hospital in close association with Department of Ophthalmology. High resolution, grey scale, real time imaging of the eye was done with ultrasonography machine using high frequency $(7.5 \mathrm{MHz})$ probe. The study was done to understand various posterior segment pathology of eyes due to ocular trauma.

\section{RESULTS}

In our series, the most common B-scan finding was traumatic cataract (47\%) and the most common posterior segment finding was vitreous haemorrhage (34\%). Most commonly traumatic cataract was found in contusion group of injuries (38.3\%) followed by penetrating injuries (21.24\%). Posterior dislocated lens was found in 3\% cases, 2 cases with rupture \& 1 with contusion. 4 cases of subluxated lens were detected, all with closed globe injuries. Vitreous haemorrhage was more common with open globe injuries than closed globe injuries (about 1.83 times), approximately $26.47 \%$ of all cases of vitreous haemorrhage were associated with rupture followed by contusion (23.53\%). Vitreous membranes were detected in 22 cases, $70 \%$ cases of which were associated with contusion injuries. 5\% posterior vitreous detachment were detected, all with contusion injuries. We found 10 cases of retinal detachment; 89 out of them (i.e. $80 \%$ ) were with open globe injuries \& $2(20 \%)$ with closed globe injuries (all contusion type). We could detect 2 cases of posterior sclera ruptures. 5 cases had total disorganisation of globe, 3 of them were ruptures with loss of intra-ocular contents in whom only complex echogenic collection was found \& no structures could be defined. 2 cases of perforating injuries were also associated with disorganisation of globe. One case of phthisis bulbi was detected which was disorganisation with intraocular calcification. In 18 cases, all with closed globe injuries, posterior segment was found to be normal. 11 cases of intraocular foreign bodies were seen by B-scan.

\section{CONCLUSIONS}

Most victims of ocular trauma are young males of less than 40 yrs. age. Closed globe injuries are more common than open globe injuries in our common day-to-day life. Home was the most common place of ocular injuries. Blunt forces are a major cause of ocular trauma. Occurrence of the different posterior segment pathologies in B-scan were: Cataract $47 \%$, Vitreous haemorrhage $34 \%$, Vitreous membranes 22\%, IOFB 12\%, Posterior dislocated lens 3\%, Subluxated lens 4\%, Retinal detachments 10\%, Posterior scleral rupture $2 \%$, Posttraumatic endophthalmitis $4 \%$ (25\% of all cases of penetrating injuries), Disorganised globe-5\%. Phthisis bulbi: $1 \%$. In B-scan study, we found that in ocular trauma lens \& vitreous are highly susceptible to damage. Traumatic cataract was the most common diagnosis followed by vitreous haemorrhage in ocular trauma. In almost all cases of open globe injuries, there is some pathology in the posterior segment. Contusion injuries are the most common cause of traumatic cataract. Subluxated and dislocated lens, vitreous haemorrhage \& membrane are most commonly found in injuries with blunt forces. Presence of vitreous haemorrhage after ocular trauma (especially open globe injuries) carries higher risk of other serious damages to the posterior segment \& a poor prognosis. B-scan was found to be extremely accurate in the diagnosis \& localisation of intraocular foreign bodies, and their nature. Vitreous was found to be the most common site of location of intraocular foreign bodies. Most of the intraocular foreign bodies were metallic. B-scan is extremely helpful in the diagnosis of posterior scleral rupture. Traumatic retinal detachment carried a poor prognosis especially in open globe injuries. Untreated penetrating injury in rural set up with delayed referral carries a high risk of posttraumatic endophthalmitis as seen in four cases.

\section{KEYWORDS}

B-scan, Ophthalmic Trauma.

HOW TO CITE THIS ARTICLE: Batham IK, Jain R, Soni VK. Role of B scan in ophthalmic trauma. J. Evolution Med. Dent. Sci. 2016;5 (104):7623-7632, DOI: 10.14260/jemds/2016/1722

Financial or Other, Competing Interest: None.

Submission 05-04-2016, Peer Review 20-07-2016,

Acceptance 26-07-2016, Published 29-12-2016.

Corresponding Author:

Dr. Vivek Kumar Soni,

Room No.44, PG Boys Hostel,

Jayarogya Hospital Campus, Gwalior-474001,

E-mail:dr.viveksoni.gmc@gmail.com

DOI: $10.14260 /$ jemds/2016/1722

\begin{abstract}
BACKGROUND
Ultrasonography was first introduced as a diagnostic tool in the field of ophthalmology in the 1950s. In spite of this, most radiologists are unfamiliar with ocular anatomy and disease as depicted sonographically largely because ophthalmic sonography has principally been the domain of ophthalmologists. With the widespread availability of high resolution grey scale, real time sonography and high frequency transducers, a gradually increasing interest in ophthalmic sonography in radiologists has become evident.
\end{abstract}


The globe is the dominant structure in the anterior orbit, and its cystic structure and superficial position is ideal for ultrasound examination. The anatomy of the eye is faithfully reproduced by high frequency ultrasound. When the light conducting media are opacified by corneal opacity cataract, haemorrhage or membranes, preventing clinical examination by ophthalmoscopy, ultrasonography is the most practical and rapid method of obtaining imaging of the posterior segment with its ability to identify the orbital walls, optic nerve, extra ocular muscles and orbital masses, ultrasound is a useful investigation in the evaluation of the orbit. Ultrasonography has the advantage of non-invasiveness, rapidity and easy accessibility, and at energy levels used for diagnostic purposes, no adverse effects have been demonstrated.

Although Computed Tomography and Magnetic Resonance Imaging are invaluable in many orbital conditions, they cannot scan in real time, lack spatial resolution and have a considerable limitation when imaging the vitreous and retina, where ultrasound contributes more to the diagnosis of diseases. Other important disadvantages in the Indian setup are the high cost and limitations of non-availability of CT and MRI as compared to sonography.

Hence, this study will attempt to assess the role of sonography as an imaging modality of choice in the diagnosis of ocular and orbital disease.

\section{Aims \& Objectives}

This was a study of 100 cases of ocular trauma by B-scan conducted from October 2007 to October 2008. It was done with the following aims \& objectives.

1. To study the various posterior segment pathologies after ocular trauma.

2. To classify the injuries with the aid of B-scan evaluation \& external examination as per the recent classification by the ocular trauma classification group to assess its usefulness in understanding the severity \& prognosis of the cases.

\section{MATERIALS AND METHODS}

This is a study of 100 cases of ocular trauma by B-scan. This study was conducted in Department of Radiodiagnosis in close association with Department of Ophthalmology in our institute. High resolution, grey scale, real time imaging of the eye was done with ultrasonography machine using high frequency $(7.5 \mathrm{MHz})$ probe. The study was done to understand various posterior segment pathology of eyes due to ocular trauma.

\section{Criteria to Select Case}

1. Any case of blunt ocular trauma with open or closed globe injury.

2. Any case of penetrating or perforating ocular trauma with or without intraocular foreign body.

A. Patients of all age \& both sexes are included in this study.

B. Examination \& Preparation of patients.
All the patients with suspected trauma were initially clinically examined in detail including recording visual acuity, torch light, examination assisted by slit lamp, direct \& indirect ophthalmoscopy \& intraocular pressure [wherever possible].

Patients with open globe injury were sent for B-scan after repair of the wound with proper aseptic precaution. After assuring the integrity, the patient was taken for examination under strict asepsis. The procedure was explained to the patient to reduce anxiety. The patient was made to lie supine with full comfort.

\section{RESULTS}

Observations

\begin{tabular}{|c|c|c|}
\hline Sex & Number of Cases & Percentage \\
\hline Male & 86 & $86 \%$ \\
\hline Female & 14 & $14 \%$ \\
\hline Total & $\mathbf{1 0 0}$ & \\
\hline \multicolumn{2}{|c|}{ Table I. Distribution of Cases according } \\
to Sex of the Patients \\
\hline
\end{tabular}

The above table shows the distribution of cases according to sex of the patient. $86 \%$ of the cases were males \& $14 \%$ cases were females. The male: female ratio was found to be 6.14:1.

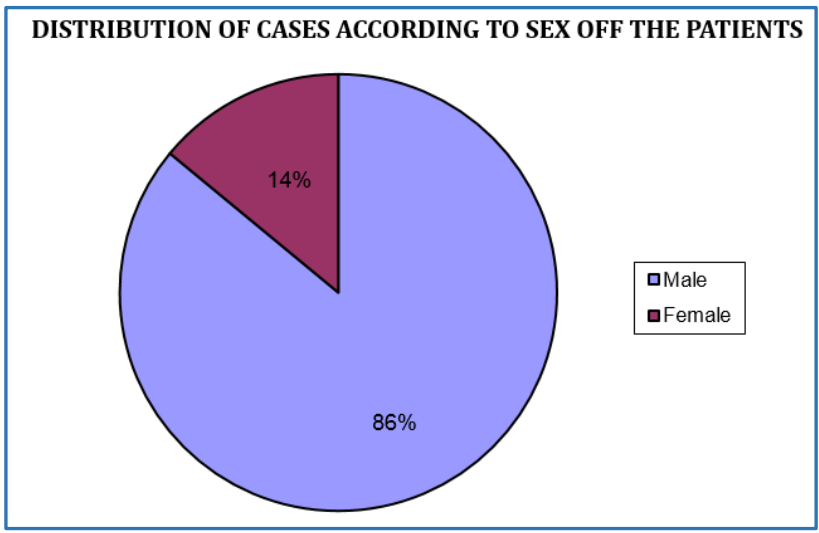

\begin{tabular}{|c|c|c|c|}
\hline Age Group & Male & Female & Total \\
\hline 0-10 years & 15 & 3 & 18 \\
\hline 11-20 Years & 17 & 1 & 18 \\
\hline 21-30 Years & 22 & 6 & 28 \\
\hline 31-40 Years & 22 & 1 & 23 \\
\hline 41-50 years & 4 & 1 & 5 \\
\hline 51-60 years & 0 & 1 & 1 \\
\hline 61-70 years & 2 & 1 & 3 \\
\hline 71-80 years & 1 & 0 & 1 \\
\hline 81-90 Years & 2 & 0 & 2 \\
\hline 91-100 Years & 1 & 0 & 1 \\
\hline \multicolumn{7}{|c|}{ Total } & $\mathbf{8 6}$ & $\mathbf{1 4}$ & $\mathbf{1 0 0}$ \\
\hline \multicolumn{7}{|c|}{ Table II. Distribution of Cases according } \\
to the Age and Sex of the Patients \\
\hline
\end{tabular}

This table shows that $87 \%$ cases were less than forty years age group of whom 76 were males \& 11 were females. $51 \%$ of the cases were between 21-40 years age group. 26\% cases were of less than 15 years of age. Average age of our patients was 26.7 years. 


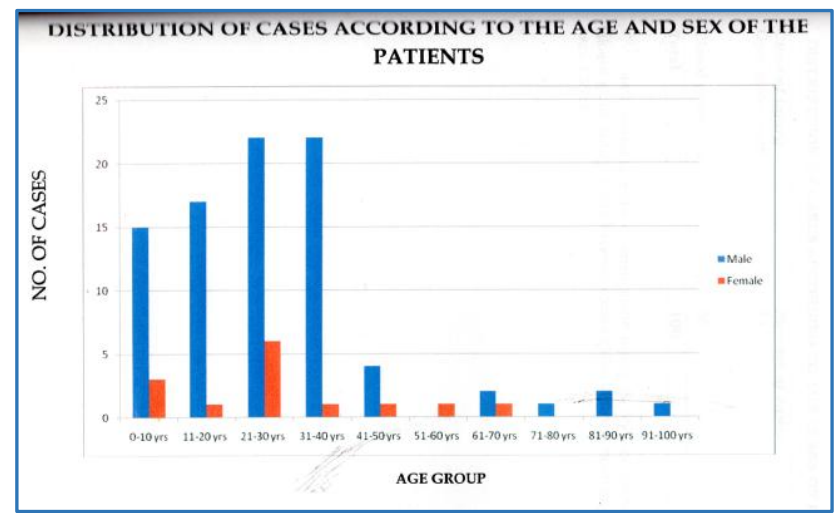

\begin{tabular}{|c|c|}
\hline Class of Injury & Number of Cases \\
\hline Open globe injury & 44 \\
\hline Closed globe injury & 56 \\
\hline Total & 100 \\
\hline \multicolumn{2}{|c|}{$\begin{array}{c}\text { Table III. Distribution of Cases according } \\
\text { to the Class of Injury }\end{array}$} \\
\hline
\end{tabular}

$44 \%$ patients were of open globe injury \& $56 \%$ of cases were of closed globe injury. Ratio between closed globe injury \& open globe injury was 1.27:1.

\begin{tabular}{|c|c|c|}
\hline Type & No. of Cases & Percentage \\
\hline Penetrating & 16 & 36.4 \\
\hline Rupture & 14 & 31.8 \\
\hline Intraocular Foreign body & 19 & 22.8 \\
\hline Perforating & 2 & 4.5 \\
\hline Mixed & 2 & 4.5 \\
\hline Total & 44 & 100 \\
\hline \multicolumn{3}{|c|}{$\begin{array}{l}\text { Table IV. Distribution of Cases according } \\
\text { to type of Injury Open Globe Injury }\end{array}$} \\
\hline
\end{tabular}

Among the 44 cases of open globe injuries, $36.4 \%$ cases were of penetrating type $\& 31.8 \%$ cases were of ruptures.

\section{Closed Globe Injury}

\begin{tabular}{|c|c|c|}
\hline Type & No. of Cases & Percentage \\
\hline Contusion & 39 & 69.9 \\
\hline Superficial Foreign Body & 6 & 10.7 \\
\hline Lamellar laceration & 2 & 3.6 \\
\hline Mixed & 9 & 16.1 \\
\hline Total & $\mathbf{5 6}$ & $\mathbf{1 0 0}$ \\
\hline
\end{tabular}

Among the 56 cases of closed globe injuries, maximum were of contusion type i.e. $69.9 \%$ \& $16.1 \%$ were of mixed types.

\section{Open Globe Injury}

\begin{tabular}{|c|c|c|}
\hline Grade & No. of Cases & Percentage \\
\hline 1. & 0 & - \\
\hline 2. & 0 & - \\
\hline 3. & 2 & 4.5 \\
\hline 4. & 24 & 54.5 \\
\hline 5. & 17 & 38.7 \\
\hline Uncooperative & 1 & 2.3 \\
\hline Total & 44 & 100 \\
\hline \multicolumn{3}{|c|}{$\begin{array}{c}\text { Table V. Distribution of Cases according } \\
\text { to Grade of Injury }\end{array}$} \\
\hline
\end{tabular}

Among the open globe injuries, $54.5 \%$ cases were of grade $4 \& 38.7 \%$ cases were of grade 5 .

Closed Globe Injury

\begin{tabular}{|c|c|c|}
\hline Grade & No. of Cases & Percentage \\
\hline 1 & 5 & 8.9 \\
\hline 2 & 6 & 10.7 \\
\hline 3 & 8 & 14.3 \\
\hline 4 & 31 & 55.4 \\
\hline 5 & 2 & 3.6 \\
\hline Uncooperative & 4 & 7.1 \\
\hline Total & $\mathbf{5 6}$ & $\mathbf{1 0 0}$ \\
\hline
\end{tabular}

Among the closed globe injuries, 55.4\% cases were of grade 4 . In 5 cases, the grading could not be done as they were too young to tell the visual acuity \& were uncooperative. One 7 yrs. child was mentally retarded \& hence the visual acuity could not be taken. $19 \%$ of all the cases had grade 5 vision. The ratio of patients having grade 5 among the two classes was 8.5:1.

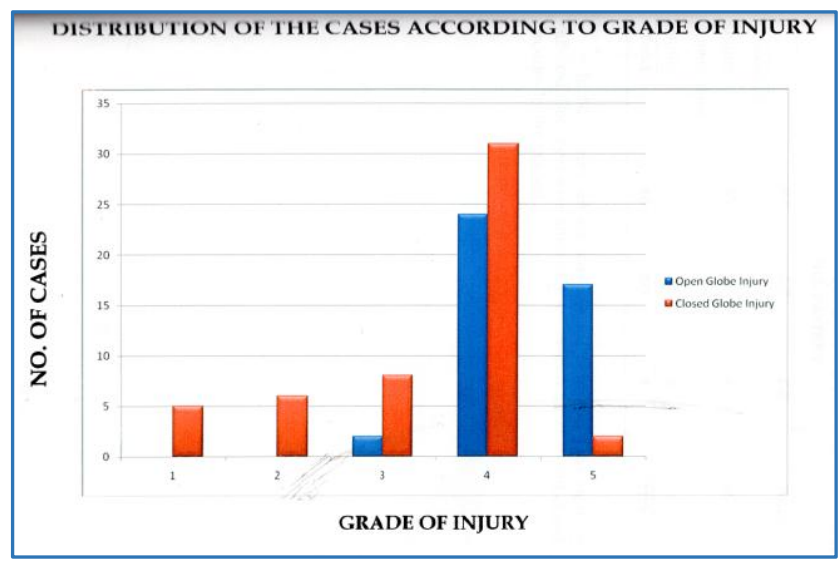

\begin{tabular}{|c|c|c|c|c|}
\hline & RE & LE & BE & Total \\
\hline Closed Globe Injury & 25 & 27 & 4 & 36 \\
\hline Open Globe Injury & 21 & 23 & 0 & 44 \\
\hline Total & $\mathbf{4 6}$ & $\mathbf{5 0}$ & $\mathbf{4}$ & $\mathbf{1 0 0}$ \\
\hline \multicolumn{5}{|c|}{ Table VI. Distribution of Cases according } \\
to the Eye Affected of the Patient \\
\hline
\end{tabular}

In $50 \%$ cases left eye was affected \& in $46 \%$ cases right eye was affected. Both eyes were affected in $4 \%$ cases \& all were with closed globe injuries by fire cracker.

\begin{tabular}{|c|l|c|c|}
\hline \multicolumn{2}{|c|}{ Zones } & No. of Cases & Percentage \\
\hline 1. & $\begin{array}{l}\text { Isolated to cornea } \\
\text { including limbus. }\end{array}$ & 23 & 52.3 \\
\hline 2. & $\begin{array}{l}\text { Corneoscleral } \\
\text { Limbus to a point } \\
5 \text { mm posterior } \\
\text { into sclera. }\end{array}$ & 17 & 38.6 \\
\hline 3. & $\begin{array}{l}\text { Posterior to the } \\
\text { anterior 5 mm of } \\
\text { sclera. }\end{array}$ & 4 & 9.1 \\
\hline \multicolumn{2}{|c|}{ Total } & $\mathbf{4 4}$ & $\mathbf{1 0 0}$ \\
\hline \multicolumn{2}{|c|}{ Table VII. Distribution of Cases according } \\
to the Zone of Involvement \\
\hline
\end{tabular}


Closed Globe Injury

\begin{tabular}{|c|c|c|c|}
\hline & Zones & No. of Cases & \% \\
\hline 1. & Limited to conjunctiva, sclera, cornea & 8 & 14.3 \\
\hline 2. & Anterior segment (Structures internal to cornea including the posterior lens \\
capsule \& pars plicata) & 12 & 21.4 \\
\hline 3. & $\begin{array}{c}\text { Posterior segment (All structures posterior to posterior lens capsule) \& pars } \\
\text { plana }\end{array}$ & 36 & 64.3 \\
\hline & Total & $\mathbf{5 5}$ & $\mathbf{1 0 0}$ \\
\hline
\end{tabular}

This table shows the distribution of cases as per zones denoted by the ocular trauma classification group. In this study, in open globe injuries, maximum involvement was in zone I (52.3\%). Among the closed globe injuries, maximum cases had zone III involvement (64.3\%)

\begin{tabular}{|c|c|c|c|c|c|c|}
\hline \multirow{3}{*}{ Grade } & \multicolumn{3}{|c|}{ Open Globe Injury } & \multicolumn{3}{|c|}{ Closed Globe Injury } \\
\hline & \multicolumn{3}{|c|}{ Zone } & \multicolumn{3}{|c|}{ Zone } \\
\hline & I & II & III & $\mathbf{I}$ & II & II \\
\hline 1 & 0 & 0 & 0 & $3(37.5 \%)$ & 0 & $2(5.5 \%)$ \\
\hline 2 & 0 & 0 & 0 & $1(12.5 \%)$ & $1(8.3 \%)$ & $4(11.1 \%)$ \\
\hline 3 & $1(4.3 \%)$ & $1(5.9 \%)$ & 0 & $2(25 \%)$ & $1(8.3 \%)$ & $7(13.9 \%)$ \\
\hline 4 & $18(78.3 \%)$ & $6(35.3 \%)$ & 0 & $2(25 \%)$ & $7(58.4 \%)$ & $22(61.1 \%)$ \\
\hline Uncooperative & $1(4.3 \%)$ & 0 & 0 & 0 & $3(25 \%)$ & $1(2.3 \%)$ \\
\hline Total & 23 & 17 & 4 & 8 & 12 & 36 \\
\hline
\end{tabular}

The above table shows the relationship between grades $\&$ zones of injury. Among open globe injuries, only $13.1 \%$ cases with zone I involvement had grade 5 visual acuity whereas $58.8 \%$ patients with zone II involvement \& $100 \%$ cases with zone III involvement had the same. Among closed globe injuries, only $25 \%$ of zone I patients had grade 4 or worse visual acuity whereas for zone II \& III they were $58.4 \%$ \& $66.6 \%$ respectively.

Distribution of Cases to show the Relationship between Grade of Injury and Zone of Involvement

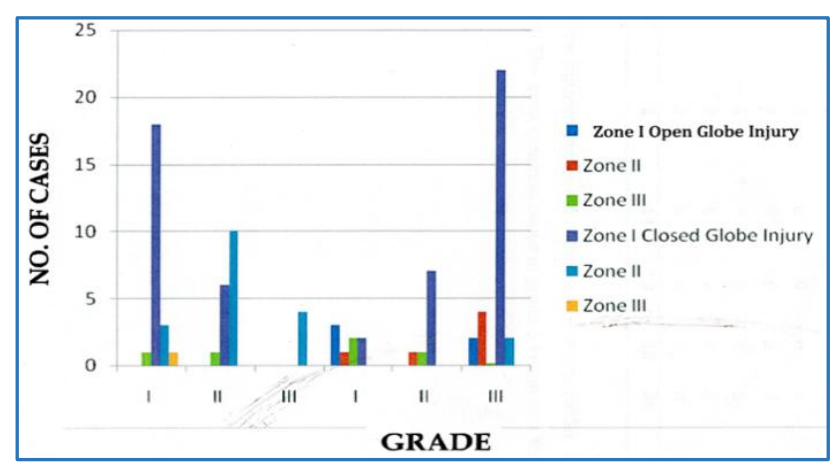

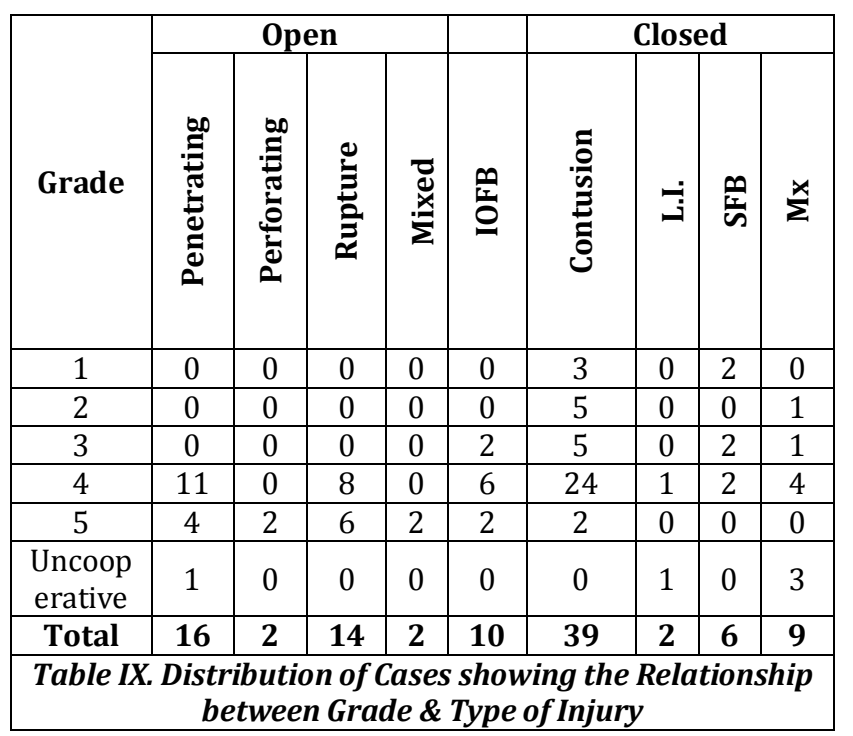

Most of the injuries presented with grade 4 vision (56\%), following by grade 5 (8\%). The most common cause of grade 5 vision was rupture.

\section{Showing the Relationship between the Type of Injury \&} Grade of Injury.

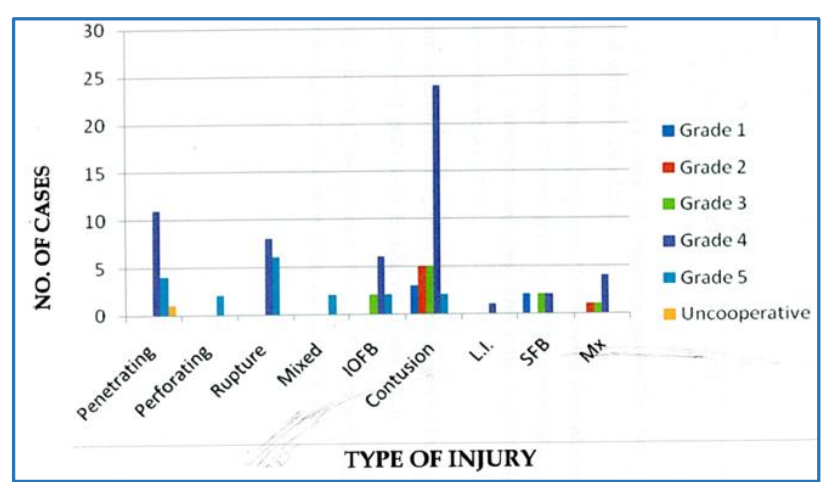

\begin{tabular}{|c|c|c|c|c|}
\hline & Domestic & Occupational & Other & Total \\
\hline $\begin{array}{c}\text { Closed } \\
\text { Injury }\end{array}$ & 43 & 9 & 4 & 56 \\
\hline $\begin{array}{c}\text { Open } \\
\text { globe } \\
\text { Injury }\end{array}$ & 18 & 20 & 6 & 14 \\
\hline Total & 61 & $\mathbf{2 9}$ & $\mathbf{1 0}$ & $\mathbf{1 0 0}$ \\
\hline \multicolumn{4}{|c|}{ Table X. Distribution of Cases according } \\
to Nature of Injury \\
\hline
\end{tabular}

$61 \%$ of injuries were of domestic nature \& $29 \%$ of cases were occupational with a ratio of 2.1:1. Among the domestic injuries, $70.5 \%$ cases were of closed globe type \& $29.5 \%$ cases were of open globe type. The closed globe injuries were more common in domestic injuries. The ratio between closed \& open globe injuries was approx. 2.4:1. Among occupational injuries, $69 \%$ cases were of open globe type \& $31 \%$ were of closed globe type \& their ratio was 2.1:1. Among closed globe injuries, $76.8 \%$ of cases were domestic $\& 16 \%$ cases were occupational $\&$ their ratio was about $4.8: 1$ 
Distribution of Cases according to the Nature of Injury

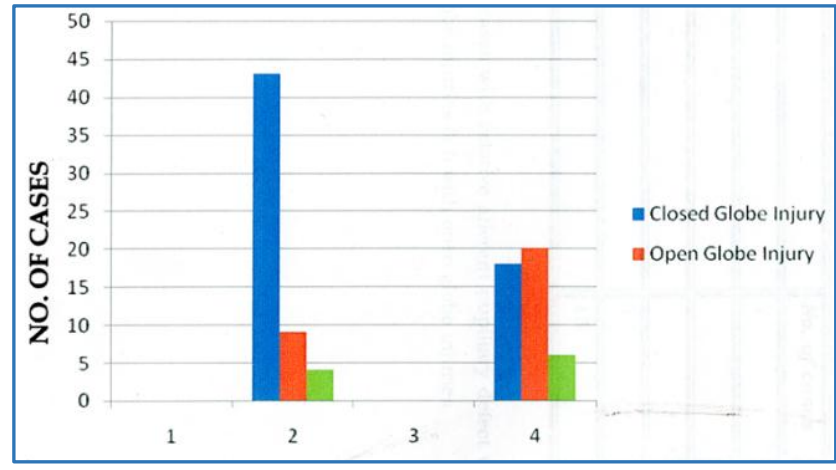

Relative Afferent Pupillary Defect

\begin{tabular}{|c|c|c|}
\hline & No. of Cases & Percentage \\
\hline Open & 6 & $40 \%$ \\
\hline & & $60 \%$ \\
\hline Closed & 9 & \\
\hline Total & $\mathbf{1 5}$ & \\
\hline $\begin{array}{r}\text { Table XI. Distribution Cases according to Presence of } \\
\text { relative Afferent Pupillary Defect }\end{array}$ \\
\hline
\end{tabular}

15 cases with relative afferent pupillary defect were noted, 9 with closed globe injuries \& 6 with open globe injuries.

\section{Relative Afferent Pupillary Defect}

\begin{tabular}{|c|c|c|}
\hline & No. of Cases & Percentage \\
\hline 1 & 0 & 0 \\
\hline 2 & 1 & 6.66 \\
\hline 3 & 1 & 6.66 \\
\hline 4 & 8 & 53.33 \\
\hline 5 & 5 & 33.33 \\
\hline Total & 15 & 100 \\
\hline \multicolumn{3}{|c|}{$\begin{array}{c}\text { Table XII. Distribution Cases with relative Afferent } \\
\text { Pupillary Defect according to Grade }\end{array}$} \\
\hline
\end{tabular}

The above table shows that $88.66 \%$ of cases with relative afferent pupillary defect had grade 4 or worse visual acuity.

Open Globe Injuries

\begin{tabular}{|c|c|c|c|c|c|c|}
\hline $\begin{array}{c}\text { Time b/w } \\
\text { I/H }\end{array}$ & & 茴 & $\stackrel{\oplus}{\underline{T}}$ & $\dot{\vec{z}}$ & 总 & $\stackrel{\pi}{\overparen{0}}$ \\
\hline 0-24 hrs. & 5 & 2 & 4 & 10 & 2 & 23 \\
\hline $\begin{array}{c}>24 \text { hrs. }-48 \\
\text { hrs. }\end{array}$ & 2 & 0 & 2 & 2 & 0 & 6 \\
\hline $\begin{array}{c}>48 \text { hrs. }-7 \\
\text { days }\end{array}$ & 6 & 0 & 0 & 2 & 0 & 6 \\
\hline $\begin{array}{c}>7 \text { days }-1 \\
\text { month }\end{array}$ & 3 & 0 & 4 & 0 & 0 & 7 \\
\hline $1-6$ months & 0 & 0 & 0 & 0 & 0 & 0 \\
\hline$>6$ months & 0 & 0 & 0 & 0 & 0 & 0 \\
\hline Total & 16 & 2 & 10 & 14 & 2 & 44 \\
\hline
\end{tabular}

Closed Globe Injuries

\begin{tabular}{|c|c|c|c|c|c|}
\hline Time b/w I/H & 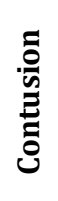 & 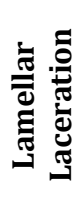 & 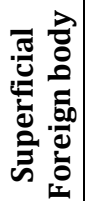 & 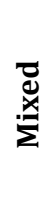 & $\underset{0}{\tilde{0}}$ \\
\hline $0-24$ hrs. & 10 & 2 & 6 & 5 & 23 \\
\hline$>24$ hrs. - 48 hrs. & 0 & 0 & 0 & 0 & 0 \\
\hline$>48$ hrs. - 7 days & 1 & 0 & 0 & 2 & 3 \\
\hline$>7$ days -1 month & 13 & 0 & 0 & 2 & 15 \\
\hline $1-6$ months & 8 & 0 & 0 & 0 & 8 \\
\hline$>6$ months & 7 & 0 & 0 & 0 & 7 \\
\hline Total & 39 & 2 & 6 & 9 & 9 \\
\hline
\end{tabular}

The above table shows that about $58 \%$ of open globe injuries presented to the hospital within $48 \mathrm{hrs}$. of injury in comparison to closed globe injuries (41.07\%). $43.75 \%$ of the penetrating injuries, $100 \%$ of the perforating \& open mixed type injuries, $60 \%$ of intraocular foreign bodies \& $85.7 \%$ of ruptures presented within $48 \mathrm{hrs}$. Compared to this, only $25.64 \%$ of the contusion injuries presented within $48 \mathrm{hrs}$.

\begin{tabular}{|c|c|c|c|c|c|c|c|c|c|c|c|c|c|c|}
\hline $\begin{array}{l}\text { Type of } \\
\text { Injury }\end{array}$ & 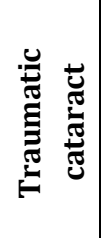 & 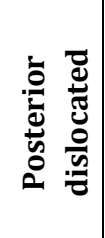 & 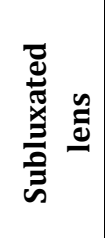 & 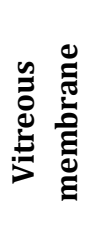 & 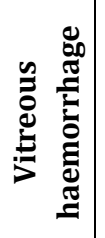 & FB & PVD & RD & 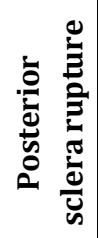 & 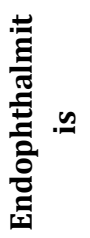 & 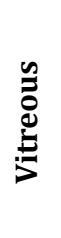 & 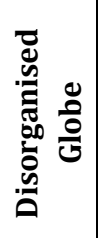 & 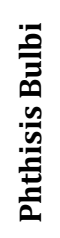 & $\begin{array}{l}\overline{\text { tg }} \\
\text { zo }\end{array}$ \\
\hline \multicolumn{15}{|c|}{ Open Globe Injury } \\
\hline Penetrating & 10 & 0 & 0 & 1 & 5 & 0 & 0 & 1 & 0 & 4 & 1 & 0 & 0 & 0 \\
\hline Rupture & 6 & 2 & 0 & 0 & 9 & 0 & 0 & 3 & 0 & 0 & 0 & 3 & 0 & 0 \\
\hline OFB & 7 & 0 & 0 & 4 & 6 & 9 & 0 & 2 & 0 & 0 & 0 & 0 & 0 & 0 \\
\hline Perforating & 0 & 0 & 0 & 0 & 0 & 0 & 0 & 0 & 0 & 0 & 0 & 0 & 0 & 0 \\
\hline Mixed & 1 & 0 & 0 & 0 & 2 & 2 & 0 & 0 & 0 & 0 & 0 & 0 & 0 & 0 \\
\hline
\end{tabular}


Closed Globe Injury

\begin{tabular}{|c|c|c|c|c|c|c|c|c|c|c|c|c|c|c|}
\hline Contusion & 18 & 1 & 3 & 16 & 8 & 0 & 5 & 2 & 0 & 0 & 0 & 0 & 1 & 8 \\
\hline Superficial & 0 & 0 & 0 & 0 & 1 & 0 & 0 & 0 & 0 & 0 & 0 & 0 & 0 & 5 \\
\hline Foreign Body & & & & & & & & & & & & & & \\
\hline Lamellar concretion & 1 & & 0 & 0 & 1 & 0 & 0 & 0 & 0 & 0 & 0 & 0 & 0 & 1 \\
\hline Mixed & 4 & 0 & 1 & 1 & 2 & 0 & 0 & 0 & 0 & 0 & 0 & 0 & 0 & 4 \\
\hline Total & $\mathbf{4 7}$ & $\mathbf{3}$ & $\mathbf{4}$ & $\mathbf{2 2}$ & $\mathbf{2 2}$ & $\mathbf{1 1}$ & $\mathbf{5}$ & $\mathbf{1 0}$ & $\mathbf{2}$ & $\mathbf{4}$ & $\mathbf{1}$ & $\mathbf{5}$ & $\mathbf{1}$ & $\mathbf{1 8}$ \\
\hline
\end{tabular}

In our series, the most common B-scan finding was traumatic cataract $(47 \%)$ \& the most common posterior segment finding was vitreous haemorrhage (34\%). Most commonly traumatic cataract was found in contusion group of injuries (38.3\%) followed by penetrating injuries $(21.24 \%)$. Posterior dislocated lens was found in $3 \%$ cases, 2 cases with rupture \& 1 with contusion. 4 cases of subluxated lens were detected, all with closed globe injuries.

Vitreous haemorrhage was more common with open globe injuries than closed globe injuries (about 1.83 times), approximately $26.47 \%$ of all cases of vitreous haemorrhage were associated with rupture followed by contusion $(23.53 \%)$ Vitreous membranes were detected in 22 cases, $70 \%$ cases of which were associated with contusion injuries. $5 \%$ posterior vitreous detachment were detected, all with contusion injuries. We found 10 cases of retinal detachment; 89 out of them (i.e. 80\%) were with open globe injuries \& 2 (20\%) with closed globe injuries (all contusion type). We could detect 2 cases of posterior sclera ruptures. 5 cases had total disorganisation of globe, 3 of them were ruptures with loss of intraocular contents in whom only complex echogenic collection was found \& no structures could be defined. 2 cases of perforating injuries were also associated with disorganisation of globe.

One case of phthisis bulbi was detected which was disorganisation with intraocular calcification. In 18 cases, all with closed globe injuries, posterior segment was found to be normal. 11 cases of intraocular foreign bodies were seen by Bscan.

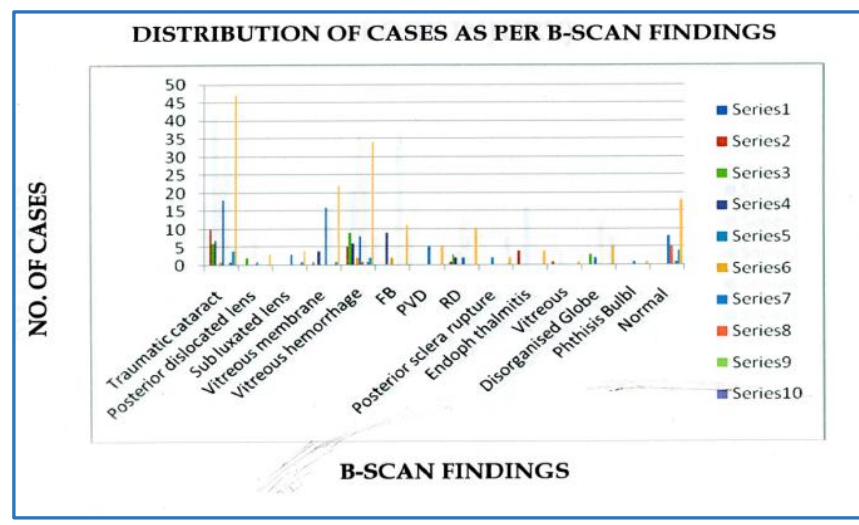

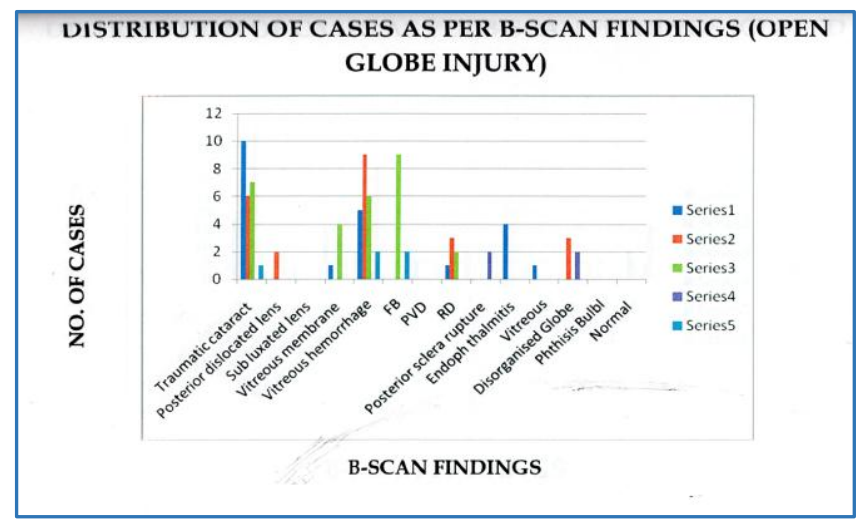

Distribution of Cases as per B-scan findings (Closed Globe Injury)

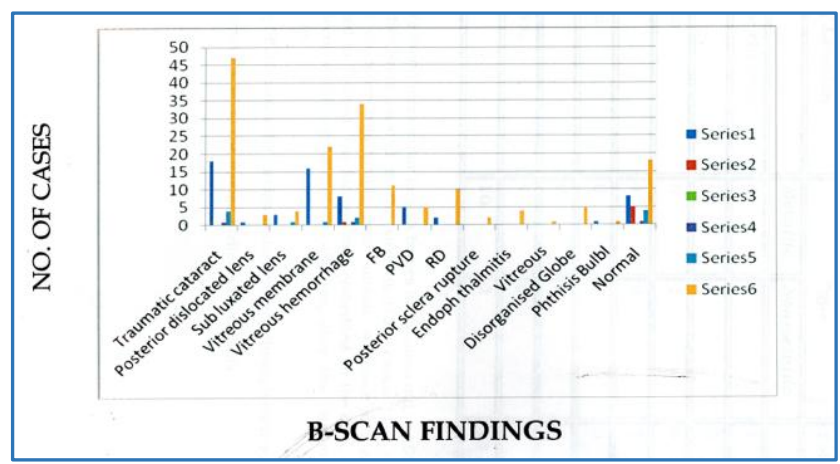

\begin{tabular}{|c|c|c|c|c|}
\hline \multirow{2}{*}{$\begin{array}{c}\text { Site of } \\
\text { Location }\end{array}$} & \multicolumn{2}{|c|}{ Type } & \multirow{2}{*}{ Total } & $\%$ \\
\cline { 2 - 5 } & Metallic & $\begin{array}{c}\text { Non- } \\
\text { metallic }\end{array}$ & & \\
\hline $\begin{array}{c}\text { Anterior } \\
\text { chamber }\end{array}$ & 0 & 1 & 1 & 8.33 \\
\hline Lens & 0 & 0 & 0 & 0 \\
\hline Vitreous & 8 & 1 & 9 & 75 \\
\hline Retina & 1 & 0 & 1 & 8.33 \\
\hline Choroid & 0 & 0 & 0 & 0 \\
\hline Sclera & 0 & 0 & 0 & 0 \\
\hline Optic No. & 1 & 0 & 1 & 8.33 \\
\hline Total & $\mathbf{1 0}$ & $\mathbf{2}$ & $\mathbf{1 2}$ & \\
\hline Table XV: IOFB according to Site of Location \& Type \\
\hline
\end{tabular}

We found intraocular foreign bodies in 12 cases out of 100 . In majority of cases, they were located in the vitreous $(75 \%$ cases). The foreign body in anterior chamber was visible from outside \& hence did not need to be diagnosed by B-scan. The foreign body embedded on the optic nerve head and retina were visible opthalmoscopically too, after the vitreous haemorrhage cleared up. In $58.3 \%$ cases, the foreign bodies entered through cornea. About $83.3 \%$ of the foreign bodies were metallic. 


\section{Distribution of intraocular foreign bodies according to their site of location}

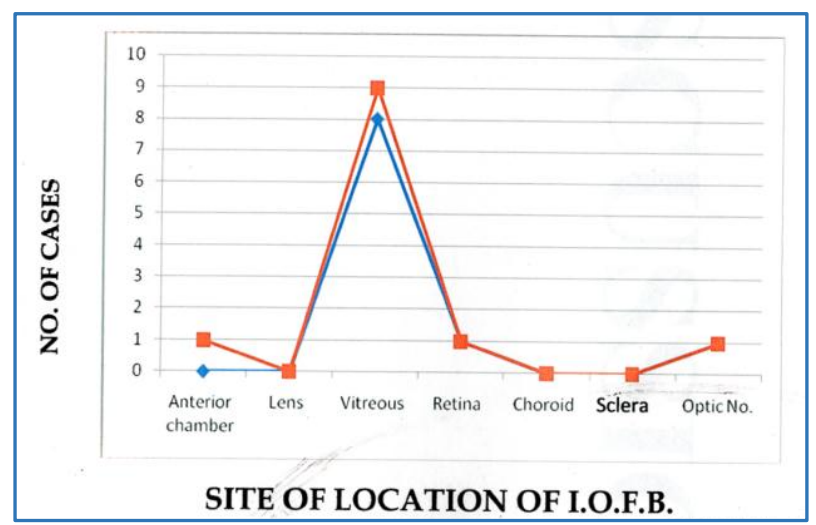

\section{DISCUSSION}

Our study of 100 cases of ocular trauma showed a definitive male preponderance (86\%), which is in close association with that quoted by Duke Elder (85-90\%). This may be because males are more involved in outdoor activities, games, etc. The male: female ratio was found to be $6.14: 1$ whereas that quoted by Jakobiec ${ }^{1}$ is 9:1.

In our study, $87 \%$ cases were less than 40 yrs. age \& 51\% belonged to the age group of 21-40 yrs. This matches with that by Jakobiec who also quoted that majority of the patients of ocular trauma were below 40 yrs. of age. High predominance of ocular trauma between 21-40 yrs. may be because of the fact that this is the age of highest activity. $18 \%$ of the patients were less than 10 yrs. old \& $26 \%$ of the patients were less than 15 yrs. This is close to the figure given by Seidelman (2 1.5\%) \& Landesberg (23.7\%). The average age of our patients was 25 yrs. which falls in the most productive age of life.

Closed globe injury in our observation was more common (56\%) than open globe injuries (44\%). This is comparable to the study by Ligett et $\mathrm{al}^{1}$ who found higher incidence of closed globe injury in an urban population. The closed globe injuries were 1.27 times more common than open globe injuries on an overall basis.

Regarding the type of injuries, in the open globe group, penetration injury was the most common, closely followed by rupture (36.4\% \& $31.8 \%$ respectively). Contusion was found to be the most common type of closed globe injury (69.6\%). Perforating injury was found in $4.5 \%$ cases (that reported by Muller Jensen was 4.4\%).

In our study, blunt forces were responsible for majority of the injuries.

Grading was done as per visual acuity at presentation. Sternberg et $\mathrm{al}^{3}$ found visual acuity to be the strongest predictor of visual outcome in ocular trauma. In our study, $93.2 \%$ of the open globe injuries had grade 4 or worse vision. $19 \%$ patients on an overall basis had grade 5 visual acuity after injury. The most common cause of grade 5 vision was rupture. This may be because of the fact that open globe injury causes more mechanical devastation, infection, chemical effects of foreign bodies \& their thermal energies also may play a role. Prognostically open globe injuries seemed to be worse. B-scan was found to be immensely helpful to assess the cause of diminished vision in ocular trauma.

In our series, we found that right eye was affected in $46 \%$ cases \& left eye was affected in $50 \%$ of cases. It was interesting to note that in our study $4 \%$ cases had both eyes affected \& all of them had closed globe injuries by firecrackers. All of them had superficial foreign bodies on the cornea. It may be possible that in blast injuries, it is difficult for the protective reflexes to come into play between the blast \& the injury \& hence the chance of involvement of both eyes is highest.

In our patients, $61 \%$ cases have domestic injuries \& $29 \%$ have occupational with a ratio of 2:1 According to Desai $P$ et $\mathrm{al}^{3}$, home was the most common place for serious eye injuries followed by work place with ratio of 1.54:1. Interestingly, closed globe injuries were 2.4 times more common than open globe injuries in domestic groups \& open globe injuries were 2.2 times commoner than closed globe injuries among occupational injuries. Probably because of the force involved \& the nature of objects were responsible for it. Conversely, domestic injuries were 4.8 times more common than occupational injuries to cause closed globe injuries.

It was interesting to note that more open globe injuries presented to the hospital within $48 \mathrm{hrs}$. than closed globe injuries.

Distribution of cases according to zonal involvement showed that most of the open globe injuries involved zone I $(52.3 \%)$. This is because cornea in the part always exposed to the outside world.

Further analysis showed that as the open globe injuries progressed from zone I to zone III, visual prognosis worsened. $13.1 \%$ of open globe injuries with zone I involvement had grade 5 vision, $58.8 \%$ with zone II involvement had the same \& $100 \%$ of zone III injures had grade 5 vision in our observation. In case of closed globe injuries, the progression from zone I to zone III involvement showed similar trends. $25 \%$ of zone I had grade 4 or worse, $58.4 \%$ of zone U \& $66.6 \%$ of zone Ill involvement had the same. Relative afferent pupillary defect was diagnosed in $15 \%$ of cases. It has been reported by various authors as a gross test for retinal \& optic nerve function \& strong predictor of the visual outcome (Dejuan $\mathrm{K}$ et $\mathrm{al}^{10}$ ). We found that $88.66 \%$ the patients with relative afferent pupillary defect have grade 4 vision. In closed globe injuries, $64.3 \%$ had zone III involvement. B-scan was extremely helpful in assessment of zonal involvement especially in closed globe injuries especially when they had hazy media. Our finding is in accordance with Pieramici et $\mathrm{al}^{4}$ in this aspect. $60 \%$ cases of relative afferent pupillary defect were associated with closed globe injuries \& $40 \%$ with open globe injuries, with a ratio of 1.5:1. In one case optic disc oedema \& in 3 cases optic atrophy was seen opthalmoscopically. In the rest of the cases the posterior segment could not be visualised (73\%). B-scan was extremely helpful in the assessment of these cases. In one case, a foreign body was found embedded on the optic nerve head. In another case, the posterior segment was found to be normal in B-scan but subsequent removal of traumatic cataract showed optic atrophy. In four cases, total retinal detachment \& in five cases foreign bodies were located along with vitreous haemorrhage. The patient with optic disc oedema subsequently developed optic atrophy. Hence, we also found that relative afferent pupillary defect is a good prognostic indicator our finding was in agreement with Ahmedieh et al. ${ }^{5}$

In B-scan of 100 cases of ocular trauma, traumatic cataract was the most common finding \& this matches with the observation by Das \& Namperurnalasamy. ${ }^{6}$ In our study, we found the occurrence to be $47 \%$. Traumatic cataract may not seem to be an important diagnosis by B-scan but it is of seminal 
importance in case of hazy media i.e. corneal oedema or hyphaema to formulate a management especially in cases of retained IOFBs, retinal detachments \& for vitrectomy procedures.

In our study, contusion was the most common cause of traumatic cataract (38.3\%), followed by penetrating injuries (21.27\%). In our study, $46.1 \%$ of pure contusion injuries had traumatic cataract. This matches with the report given by Davison in 1936 that traumatic cataracts occur with high incidence even with minor concussions.

We found posterior dislocated lens in $3 \%$ cases. All the cases were due to blunt injuries $(66.6 \%$ cases in ruptures \& $33.3 \%$ in contusion). Incidentally, one of these cases was a high myopia (-15D). All these cases were advised removal of the lens.

Subluxated lens was found in $4 \%$ cases, all with closed globe injuries \& $75 \%$ of them due to contusion. One of these cases had associated iridodialysis \& vitreous herniating into the anterior chamber with secondary glaucoma \& PVD. Glaucoma was managed \& then the subluxated lens was removed \& the iridodialysis was repaired. With aphakic glasses the patient improved to $6 / 36$ in the injured eye after 6 weeks of surgery. Another case was found to have macular oedema after surgery. Vitreous membranes were found in $22 \%$ cases, most of whom $(72.7 \%)$ were found in contusion injuries in patients who presented late for ocular examination to the hospital. They may represent resolved vitreous haemorrhages or vitreous degeneration after trauma. Approximately, 18.2\% of vitreous membranes were associated with intraocular foreign bodies.

In our study, vitreous haemorrhage was the most common posterior segment finding in B-scan \& its incidence was found to be $34 \%$. Das \& Namperumalasamy in 1983 reported in their study, 43 out of 175 cases of ocular trauma i.e. $24.6 \%$ had vitreous haemorrhage, the second most common diagnosis after traumatic cataract in ocular trauma. This matches with our findings.

Kwong et $\mathrm{al}^{7}$ found an unusually high incidence $(70 \%)$ of vitreous haemorrhage in their series of 71 cases. Rupture, we found, was the most common cause of vitreous haemorrhage (26\%), closely followed by contusions (24\%). 64.7\% cases of vitreous haemorrhages were found in open globe injuries \& 2 times more common than in closed globe injuries. But blunt forces (including ruptures) were responsible for majority of cases of vitreous haemorrhage.

Retinal detachment had high association with vitreous haemorrhage \& in $90 \%$ cases of detachments, vitreous haemorrhagic finding, $66 \%$ of intraocular foreign bodies were associated with vitreous haemorrhage. DeJuan et al ${ }^{10}$ also found vitreous haemorrhage as a poor prognostic sign in penetrating ocular injuries. Hence, presence of vitreous haemorrhage in ocular trauma should make one suspicious about serious posterior segment pathologies e.g. retinal detachments, IOFB, etc. In our setup, we conservatively managed the simple vitreous haemorrhages \& the ones with retinal detachments \& intraocular foreign bodies were advised immediate vitreoretinal surgery. Followup of these patients were not available.

Intraocular foreign bodies could be identified in $12 \%$ cases. Our finding matches to the similar finding by Das \& Namperumalasamy (12\% i.e. 22 of 175 cases). In our series, $91 \%$ of the foreign bodies were diagnosed by B-scan. In one case, the foreign body was visible in the anterior chamber from outside \& B-scan was not needed to diagnose it.

In our study, vitreous was the most common site of location of foreign bodies (75\%). Williams et al also found vitreous as the most common site of location of intraocular foreign bodies (60\%). Duke Elder ${ }^{7}$ quoted that $70 \%$ of the foreign bodies are found in the posterior segment. Cornea was the most common site of entry in our cases, is similar to the finding noticed by Williams et al ${ }^{11}$ \& Khani et al. ${ }^{12}$

About $83 \%$ of intraocular foreign bodies were metallic which is comparable to the results by Williams et $\mathrm{al}^{8}(90 \%)$. This may be because to the fact that metallic foreign bodies are usually sharp \& have high penetrating velocity. About $25 \%$ of IOFBs were associated with retinal detachment \& 58\% were associated with vitreous haemorrhage. $34 \%$ of IOFBs were associated with grade 5 vision. Hence, presence of intraocular foreign bodies was a bad prognostic factor found in our study. In two cases of perforating injuries, both due to gunshots, there were entry wounds visible anteriorly. B-scan showed total disorganisation of all intraocular details \& posterior scleral rupture (double perforation) \& collapse of the globe. CT scan demonstrated the pellets near the apex of the orbit \& confirmed posterior scleral rupture. Russell SR et al ${ }^{13}$ reported that B-scan could detect only $23 \%$ cases of scleral ruptures. Both these eyes were subsequently enucleated after primary repair. Occurrence of posterior vitreous detachment in our series was $5 \%$. All the cases were associated with contusion injuries. Kwong et $\mathrm{al}^{7}$ found them to be $7.04 \%$. We found that $10 \%$ of our series had retinal detachment. Kwong et al reported $31 \%$ of retinal detachments in their cases. $80 \%$ of the detachments were associated with open globe injuries \& most of them had zone II \& III involvement. Rupture was found to be the most common cause $(30 \%)$. Among the closed globe groups, contusion was the only cause of retinal detachments. One case with severe contusion injury reported within 1 day had retinal detachment \& was operated for retinal detachment. His vision improved to $6 / 60$ in the injured eye after retinal detachment surgery. The other case was a high myopia (-25D) with retinal detachment of long duration ( 5 yrs.) \& had total retinal detachment with proliferative vitreoretinopathy \& no PL. 75\% cases of open globe injuries with retinal detachment had grade 5 vision.

In the absence of prompt referral, retinal detachments in open globe injuries have a bad prognosis, in the present circumstances.

Blunt trauma (including ruptures) was responsible for majority $(50 \%)$ of cases of retinal detachments in our observation \& this matches to the finding by Giovinazzo et al ${ }^{11}$ $\&$ Goffstein $\mathrm{Ct}_{\text {et }} \mathrm{al}^{1}$ who found the same to be $70-86 \%$.

Posttraumatic endophthalmitis was present in $4 \%$ cases, all with penetrating injuries. In $75 \%$ of the cases, the injury occurred through zone I \& $25 \%$ had zone II involvement. All zone I involvement injured the lens, in this way our observation is in agreement with that of Thompson et al ${ }^{12}$ who found in their analysis, lens injury as a very significant risk factor for the development of endophthalmitis in penetrating injuries. One case, an 11-year-old boy had grade $4+$ flare $\&$ cells \& on B-scan was found to have exudates in the anterior vitreous \& traumatic cataract. Clinically, it did not seem like endophthalmitis \& the culture was negative. So the case was graded as vitritis \& was put on systemic \& topical steroids until the inflammation abated \& then was operated for traumatic 
cataract under steroid cover \& was advised vitreous surgery under guarded prognosis. B-scan was extremely helpful to us to assess \& formulate the management of this case.

In our series, endophthalmitis was found in $24 \%$ of the penetrating injuries. Brinton et al.13 reported $2-7 \%$ of endophthalmitis in penetrating trauma. But rural back ground, initial negligence \& poor referral facility found in all our cases were probably the main responsible factors for such a high incidence. Considering the same, our results were matchable to that of Boldt $\mathrm{HC}$ et al ${ }^{16}$ who reported $30 \%$ endophthalmitis among rural patients. Total $5 \%$ of cases had disorganisation of globe. 3 cases were of rupture where there was expulsion of intraocular contents. In B-scan, these cases appeared as diffuse complex echogenic collection. Two cases of perforations also had similar findings. As the structures could not be separately delineated, we kept them as a separate category. One case of phthisis bulbi was noted in the context of contusion injuries of long duration. Intraocular calcification \& bone formation was noted in this case. 18 cases of closed globe injuries had normal B-scan finding in the posterior segment but none with open globe injuries. Hence, we can see that in open globe injury some kind of posterior segment involvement is detectable in almost all the cases, whereas in closed globe injury $32 \%$ cases escaped any detectable posterior segment changes in B-scan.

\section{SUMMARY \& CONCLUSIONS}

This was a study of 100 cases of ocular trauma by B-scan, conducted in the Jayarogya Group of Hospitals, in close association with Department of Ophthalmology, in Gajra Raja Medical College Gwalior. 100 cases of ocular trauma were chosen irrespective of age or sex \& examined first clinically \& then by B-scan.

A $7 \mathrm{MHz}$ probe was used for evaluation through closed lids \& various pathological changes were noted. Injuries were classified on the basis of the external findings, visual acuity at the time of presentation \& B-scan findings as per the classification suggested by The Ocular Trauma Classification group in 1997.

\section{Our Major conclusions have been as below}

1. Most victims of ocular trauma are young males of less than 40 yrs. age.

2. Closed globe injuries are more common than open globe injuries in our common day-to-day life.

3. Home was the most common place of ocular injuries.

4. Blunt forces are a major cause of ocular trauma.

5. Occurrence of the different posterior segment pathologies in B-scan were:

- Cataract $47 \%$.

- Vitreous haemorrhage $34 \%$

- Vitreous membranes $22 \%$.

- IOFB: $12 \%$.

- Posterior dislocated lens: $3 \%$

- Subluxated lens: $4 \%$.

- Retinal detachments: $10 \%$.

- Posterior scleral rupture: $2 \%$.

- Posttraumatic endophthalmitis $4 \%$ (25\% of all cases of penetrating injuries).

- Disorganised globe $-5 \%$. Phthisis bulbi: $1 \%$.

6. In B-scan study, we found that in ocular trauma, lens \& vitreous are highly susceptible to damage. Traumatic cataract was the most common diagnosis followed by vitreous haemorrhage in ocular trauma.

7. In almost all cases of open globe injuries, there is some pathology in the posterior segment.

8. Contusion injuries are the most common cause of traumatic cataract.

9. Subluxated and dislocated lens, vitreous haemorrhage \& membrane are most commonly found in injuries with blunt forces.

10. Presence of vitreous haemorrhage after ocular trauma (especially open globe injuries) carries higher risk of other serious damages to the posterior segment $\&$ a poor prognosis.

11. B-scan was found to be extremely accurate in the diagnosis \& localisation of intraocular foreign bodies and their nature

12. Vitreous was found to be the most common site of location of intraocular foreign bodies.

13. Most of the intraocular foreign bodies were metallic.

14. B-scan was extremely helpful in the diagnosis of posterior scleral rupture.

15. Traumatic retinal detachment carried a poor prognosis especially in open globe injuries.

16. Untreated penetrating injury in rural setup with delayed referral carries a high risk of posttraumatic endophthalmitis as seen in four cases.

17. The classification suggested by the ocular trauma classification group was found to be extremely useful by us. Some of our findings support this:

A. The concept of zones was extremely useful. In both open \& closed globe injuries as the injury progressed from zone I to III, the visual prognosis worsened. Bscan was found to be extremely important in assignment of zones especially in closed globe injuries, hazy media.

B. Visual prognosis (grade) at presentation was found to be a very strong predictor of visual outcome. Cases presenting with grade 5 (No PL) carried bad prognosis.

C. Presence of relative afferent pupillary defect carries a poor prognosis as it denotes injury to optic nerve \& retina.

D. Open globe injuries especially ruptures were associated with higher chance of bad prognosis.

In this way, we find that B-scan was extremely helpful in the assessment of the various posterior segment pathologies in ocular trauma \& the new classification system was enormously helpful in the assessment of the prognosis.

\section{REFERENCES}

1. Jakobiec F. Text Book of Ophthalmology chap. 370, p 5179.

2. Goffdstein R, Burton TC. Differentiation traumatic from nontraumatic retinal detachment. Ophthalmology 1982;89(4):361-8.

3. Sternberg P, DeJuan K, Michels RG, et al. Multivariate analysis of prognostic factors in penetrating ocular injuries. Am J Ophthalmol1984;98(4):467-72

4. Pieramici DJ, Sternberg P, Aaberg TM, et al. A system of classifying mechanical injuries of the eye (globe). The 
Ocular Trauma Classification Group. Am J Ophthalmol 1997;123(6):820-31.

5. Ahmedieh H, Soheilian M, Sajjadi H, et al. Vitrectomy in ocular trauma factors influencing final visual outcome. Retina 1993;13(2):107-13.

6. Das T, Namperumalasamy P. Ocular ultra sound in preoperative evaluation of posterior segment of the eye. Ind J Ophthal 1983;31(7):1022-24.

7. Duke Elder S. System of ophthalmology. Vol. 6. Injuries. London: Henry Kempton 1954:p. 5799.

8. Duke elder S. System of ophthalmology. Vol. 6. London: Henry Kempton 1954:5717-5718.

9. Kwong JS, Munk PL, Lin DTC, et al. Real time sonography in ocular trauma. American Journal of Roentgenology 1992;158(1):179-82.

10. DeJuan E, Sternberg P, Michels RG. Penetrating ocular injuries: type of injuries and visual result. Ophthalmology 1983;90(11):1318-22.
11. Williams DF, Mieler WF, Abrams GW, et al. Results and prognostic factors in penetrating ocular injuries with retained intraocular foreign bodies. Ophthalmology 1988;95(7):911-6.

12. Khani SC, Mukai S. Posterior segment intraocular foreign bodies. Int Ophthalmol Clin 1995;35(1):151-61

13. Russell SR, Olsen KR, Folk JC. Predictors of scleral rupture \& role of vitrectomy in severe blunt ocular trauma. Am J Ophthalmol 1988;105(3):253-7.

14. Thompson WS, Rubsamen PE, Flynn HW, et al. Endophthalmitis after penetrating trauma: risk factors \& visual acuity outcomes. Ophthalmology 1995;102(11):1696-701.

15. Brinton GS, Topping TM, Hyndiuk RA, et al. Posttraumatic endophthalmitis. Arch Ophthalmol 1984;102(4):547-50

16. Boldt HC, Pulindo JS, Blodi CF, et al. Rural endophthalmitis. Ophthalmology 1989;96(12):1722-6. 